\title{
The association between knowledge of HPV and feelings of stigma, shame and anxiety
}

\author{
J Waller, L A V Marlow, J Wardle
}

Sex Transm Infect 2007;83:155-159. doi: 10.1136/sti.2006.023333

See end of article for authors' affiliations

.....................

Correspondence to: Dr Jo Waller, Cance Research UK Health Behaviour Unit, Department of Epidemiology and Public Health, University College London, 2-16 Torrington Place, London WC1E 6BT, UK; j.waller@ucl.ac.uk

Accepted 2 October 2006

\begin{abstract}
Objectives: To test the hypotheses that (1) women who know that human papillomavirus (HPV) is sexually transmitted will expect to experience higher levels of stigma, shame and anxiety if they test positive for the virus than women who are not aware of the mode of transmission and (2) women who are aware of the high prevalence of HPV infection will expect to experience lower levels of stigma, shame and anxiety than women who underestimate its prevalence.

Methods: A web-based survey in which information about HPV was manipulated to generate a $2 \times 2$ design (awareness that HPV is sexually transmitted $v$ no awareness; awareness of the high prevalence of HPV $v$ no awareness). Participants $(n=811)$ were female students. They were asked to imagine that they had tested positive for HPV. Outcome measures were expected stigma, shame and anxiety.

Results: Great differences were observed in emotional reactions to imagining testing HPV positive between the four groups based on knowledge of HPV. Knowledge of the prevalence was associated with lower levels of stigma, shame and anxiety. Knowledge that HPV is sexually transmitted was associated with higher levels of stigma and shame, but not anxiety. Women who knew that HPV is sexually transmitted but not that it is highly prevalent had the highest scores for stigma and shame.

Conclusions: Raising public awareness of the sexually transmitted nature of HPV has the potential to increase women's feelings of stigma and shame if they test positive for the virus. However, our findings suggest that ensuring women's awareness of HPV being common may reduce these feelings and also reduce anxiety, perhaps by "normalising" the infection.
\end{abstract}

$\mathrm{H}$ uman papillomavirus (HPV) is a common sexually transmitted infection (STI). A recent study in Manchester, UK, found that $40 \%$ of women aged $20-$ 24 years tested positive for high-risk types of the virus. ${ }^{1}$ Strong evidence for the role of persistent high-risk HPV in the aetiology of cervical cancer ${ }^{2}$ has resulted in HPV testing being recommended as part of cervical screening in the US, and work is under way to consider its role in the National Screening Programme in the UK. Prophylactic HPV vaccination has recently been licensed for use in Europe ${ }^{3}$ and is recommended for girls aged $11-12$ years in the US. ${ }^{4}$

Despite the enormous progress in research on HPV, most of the general public remain unaware of the virus. ${ }^{5}$ But inevitably, as testing and vaccination become more widely used, public awareness will grow, and this could change the way that cervical cancer is perceived. Some researchers and clinicians have expressed concern that greater public awareness of the link with HPV could lead to stigmatisation of cervical cancer and perhaps even reluctance to attend for screening because of the sexually transmitted nature of the virus. This idea is consistent with studies of screening for other STIs (eg, chlamydia, ${ }^{6}$ gonorrhoea and $\mathrm{HIV}^{7}$ ) and has received some support from qualitative studies of HPV testing. Women testing positive for HPV in the context of cervical screening report feelings of stigma and shame, but only when they are aware that the virus is sexually transmitted. ${ }^{8}$ There is also evidence that receiving a positive HPV result is associated with higher anxiety than simply having an abnormal smear result. ${ }^{9}{ }^{10}$

One way of reducing negative feelings may be to emphasise the high prevalence of HPV, thereby "normalising" infection. This is consistent with theories of stigma which propose that "standards ... derive in part from the prevalence of the phenomenon that is being judged" ${ }^{11}$ Experimental research has also shown that infections perceived to be common are judged to be less serious than those perceived to be rare, ${ }^{12}$ so anxiety about HPV might be less if it were known to be common. In addition, qualitative work with HPV positive women indicates that understanding the high prevalence of the virus may reduce feelings of stigma and shame. ${ }^{8}$ If this observation can be confirmed in quantitative research, it has implications for public health messages about HPV.

This study examined differences in women's expected responses to testing positive for HPV. Information about the cause and prevalence of the virus was manipulated to test two hypotheses:

1. Women who know that HPV is sexually transmitted will expect to experience higher levels of stigma, shame and anxiety if they test positive for the virus than women who are not aware of the mode of transmission.

2. Women who are aware of the high prevalence of HPV infection will expect to experience lower levels of stigma, shame and anxiety than women who underestimate the prevalence of infection.

\section{METHODS}

\section{Study design}

The study was web based, using a quasi-experimental design to manipulate knowledge of HPV. All participants were provided with basic information about HPV and cervical cancer (points 1-5 in box 1), but details of the mode of transmission and the prevalence were manipulated so women received: (1) no additional information; (2) point 6 (prevalence) only; (3) point 7 (transmission) only; or (4) points 6 and 7.

Abbreviations: HPV, human papillomavirus; STI, sexually transmitted infection 
Box 1 Information on human papilloma virus provided at the start of the survey

1. A virus called human papillomavirus (HPV) is now known to be involved in the development of cervical cancer (cancer of the cervix or neck of the womb).

2. For most women, the immune system clears the virus and there are no health problems associated with it.

3. If infection persists, it can lead to abnormalities in the cells of the cervix.

4. Regular attendance for cervical smear tests can help to detect the cell changes that are caused by HPV. These can then be treated effectively.

5. Both men and women can have the virus, but it rarely causes any problems for men.

6. It is thought that around $70 \%$ of people will be infected with HPV at some point during their lives-it is very common.

7. The virus is sexually transmitted.

\section{Participants}

Participants were female students at a London university. A recruitment email was sent to all students with a link to the website where the questionnaire could be completed online. Power calculations based on pilot work indicated that a sample size of at least 150 in each of the four groups would give $80 \%$ power to detect a small effect size for between-group differences in stigma, shame and anxiety scores, with a significance level of 0.05 . A total of 909 female participants completed the questionnaire in the first 7 days that it was online, after which the website was inactivated.

\section{Measures \\ Stigma, shame and anxiety \\ Participants were asked to imagine that they had been tested for HPV and the result had been positive. They then answered questions relating to how they would expect to feel in this situation and how other people would behave towards them. The 17 items (table 1) measuring various aspects of stigma, shame and anxiety were adapted from work by Cunningham et $a l^{1314}$ on other STIs, and qualitative work in the HPV field. All items were rated on a 4-point scale. Factor analysis of pilot data $(\mathrm{n}=90)$ yielded three scales with good internal reliability. Factor analysis in this sample confirmed the three-factor structure: stigma ( 8 items, $\alpha=0.90$ ), shame (5 items, $\alpha=0.87$ ) and anxiety (4 items, $\alpha=0.73$ ).}

\section{Knowledge of prevalence and sexually transmitted nature of HPV}

Two questions were used to assess knowledge of HPV at the end of the survey; both were multiple-choice questions with one correct answer. The first question asked "What do you think causes HPV?". Participants could select one of eight answers, including the correct option "HPV is sexually transmitted". The second question asked "About how many people do you think will get HPV at some point in their lives?". Participants had to choose a response between $0 \%$ and $100 \%$, with an additional option for "don't know". Answers from 60\% to 100\% were coded as correct for the purposes of this study because all these responses indicated awareness of the high prevalence of HPV. ${ }^{\mathrm{i}}$

iOnly 2 participants endorsed $100 \%$ and 11 endorsed $90 \%$, so most women in this group were within $10 \%$ of the correct answer.
We also asked participants whether they had ever heard of HPV before taking part in the study.

\section{Demographic characteristics}

Demographic characteristics were assessed with simple questions on age, marital status, subject of study, religion, practising of religion and ethnicity.

\section{Procedure}

An email was circulated to all students of University College London asking them to complete the online survey about "reactions to health information" and informing them that participants would be entered into a $£ 100$ prize draw. The survey was set up so that participants were randomly allocated to one of the four information conditions described earlier. Information was presented in bullet-point form, and participants were asked to click a box next to each point to indicate they had read it before moving on to the next stage. The response section was designed so that participants could not progress to the next page until all questions had been completed, so there were no missing data. Times of starting and finishing were recorded so that people taking an excessively long time could be excluded from analyses, thus minimising the chance of including people who were looking up information about HPV or discussing the survey as they were doing it. Data were captured in an Access file and exported to SPSS V.13 for analysis.

\section{RESULTS}

Sample

The mean time taken to complete the survey was $<8 \mathrm{~min}$. After eliminating major outliers (ie, those taking $>1 \mathrm{~h}$ ), we excluded anyone whose time was more than three standard deviations above the mean $(\mathrm{n}=24)$. Participants who were $>30$ years old $(\mathrm{n}=70)$ or were not students $(\mathrm{n}=4)$ were also excluded to keep the sample homogeneous. The final sample used for analysis comprised 811 participants. Table 2 shows the demographic characteristics of the sample.

\section{Knowledge categorisation}

Because we were interested in women's actual knowledge of HPV, rather than the information they had been given, we categorised participants on the basis of the two knowledge questions completed at the end of the survey-that is, whether they knew that HPV is sexually transmitted and whether they were aware of the high lifetime prevalence of the virus. Classification in this way generated four knowledge groups (box 2).

Most of the sample (58\%) reported having heard of HPV before, so knowledge did not correspond exactly with the information that women had been given.

\section{Between-group differences in stigma, shame and anxiety}

Table 1 shows the number of people in each group who responded positively (ie, with a score of 3-4 out of 4) to each item. $\chi^{2}$ tests found differences between groups for all the items on the shame and anxiety scales, and for five of the eight items on the stigma scale.

Total scores were calculated for the three outcome scales: stigma, shame and anxiety. These were standardised to take account of the different number of items in each scale. Figure 1 shows the scores for each outcome for the four knowledge groups.

One way analysis of variance

One way analysis of variance confirmed that stigma $\left(\mathrm{F}_{3,807}=5.31, \mathrm{p}=0.001\right)$, shame $\left(\mathrm{F}_{3,807}=17.60, \mathrm{p}<0.001\right)$ and 
Table 1 Between-group differences in response to each item (number of respondents agreeing with each item with percentages in brackets)

\begin{tabular}{|c|c|c|c|c|c|}
\hline Scale/items & $\begin{array}{l}\text { Group 1, no } \\
\text { knowledge } \\
(n=138 \text { ) }\end{array}$ & $\begin{array}{l}\text { Group 2, } \\
\text { STI only } \\
(n=245)\end{array}$ & $\begin{array}{l}\text { Group 3, } \\
\text { prevalence only } \\
(n=121)\end{array}$ & $\begin{array}{l}\text { Group 4, STI } \\
\text { and prevalence } \\
(n=307)\end{array}$ & $\begin{array}{l}\chi^{2}(d f) \text { for } \\
\text { difference }\end{array}$ \\
\hline \multicolumn{6}{|l|}{ Stigma (Agree/strongly agree) } \\
\hline People would avoid me & $22(15.9)$ & $36(14.7)$ & $8(6.6)$ & $35(11.4)$ & $6.8(3), \mathrm{NS}$ \\
\hline People would think badly of me & $32(23.2)$ & $90(36.7)$ & $21(17.4)$ & $100(32.6)$ & $18.5(3), p<0001$ \\
\hline People would blame me & $25(18.1)$ & 89 (36.3) & $13(10.7)$ & $106(34.5)$ & $38.7(3), p<0.001$ \\
\hline People would think I was unclean & $40(29.0)$ & $81(33.1)$ & $32(26.4)$ & $95(30.9)$ & $1.9(3)$, NS \\
\hline People would not want to be friends with me & $7(5.1)$ & $14(5.7)$ & $2(1.7)$ & $9(2.9)$ & $5.0(3), \mathrm{NS}$ \\
\hline $\begin{array}{l}\text { People would not want to have a sexual } \\
\text { relationship with me }\end{array}$ & 78 (56.5) & $168(68.6)$ & $68(56.2)$ & $183(59.6)$ & $8.5(3), p=0.04$ \\
\hline People would be uncomfortable around me & $34(24.6)$ & $48(19.6)$ & 18 (14.9) & $41(13.4)$ & $9.9(3), p=0.02$ \\
\hline People would be angry with me & $7(5.1)$ & $25(10.2)$ & $4(3.3)$ & $18(5.9)$ & $8.0(3), p=0.05$ \\
\hline \multicolumn{6}{|l|}{ Shame (Quite/very) } \\
\hline How responsible would you feel? & 44 (31.9) & $135(55.1)$ & $34(28.1)$ & $141(45.9)$ & $33.4(3), p<0.001$ \\
\hline How ashamed would you feel? & $22(15.9)$ & $67(27.3)$ & $12(9.9)$ & $66(21.5)$ & $17.2(3), p=0.001$ \\
\hline How embarrassed would you feel? & $33(23.9)$ & $85(34.7)$ & $16(13.2)$ & $85(27.7)$ & $19.7(3), p<0.001$ \\
\hline How guilty would you feel? & $13(9.4)$ & $61(24.9)$ & $9(7.4)$ & 55 (17.9) & $24.5(3), p<0.001$ \\
\hline How disappointed in yourself would you feel? & $36(26.1)$ & $93(38.0)$ & $21(17.4)$ & $90(29.3)$ & $17.8(3), p<0.001$ \\
\hline \multicolumn{6}{|l|}{ Anxiety (Quite/very) } \\
\hline How anxious would you feel? & $101(73.2)$ & $179(73.1)$ & $72(59.5)$ & $159(51.8)$ & $34.9(3), p<0.001$ \\
\hline How scared would you feel? & $81(58.7)$ & $136(55.5)$ & $54(44.6)$ & $118(38.4)$ & $23.7(3), p<0.001$ \\
\hline How angry would you feel? & $28(20.3)$ & $71(29.0)$ & 20 (16.5) & $73(23.8)$ & $8.1(3), p=0.04$ \\
\hline People would pity me & 79 (57.2) & $100(40.8)$ & $57(47.1)$ & $108(35.2)$ & $20.4(3), p<0.001$ \\
\hline
\end{tabular}

anxiety $\left(\mathrm{F}_{3,807}=10.33, \mathrm{p}<0.001\right)$ all varied between the four knowledge groups.

We used retrospective analyses (Scheffé tests) to examine differences in means between the four groups on each outcome measure, and identify where the between-group differences occurred. Stigma was significantly higher in the "STI only" than in the "Prevalence only" group (mean difference 2.31, $\mathrm{p}=0.004$ ). Shame was higher in the "STI only" group than in the "No knowledge", "Prevalence only" and "STI and prevalence" groups (mean differences were $3.97(\mathrm{p}<0.001)$, $5.52(\mathrm{p}<0.001)$ and $1.89(\mathrm{p}=0.036)$, respectively). Shame was also significantly higher in the "STI and prevalence" group than in the "Prevalence only" group (mean difference 3.64, $\mathrm{p}<0.001$ ). Anxiety was significantly higher in the "No knowledge" and "STI only" groups than in the "STI and prevalence" group (mean differences were $2.77 \quad(\mathrm{p}<0.001)$ and 2.38 $(\mathrm{p}<0.001)$, respectively).

\section{Two-by-two analysis of variance}

A $2 \times 2$ analysis of variance was used to look at the effects of knowledge of STI and its prevalence, and to see whether there was an interaction between them. Knowledge of STI was significantly associated with stigma $\left(\mathrm{F}_{1,807}=7.70, \mathrm{p}=0.001\right)$ and shame $\left(\mathrm{F}_{1,807}=44.83, \mathrm{p}<0.001\right)$ but not with anxiety. Prevalence knowledge was significantly associated with stigma $\left(F_{1,807}=9.18, p=0.003\right)$, shame $\left(F_{1,807}=11.24, p=0.001\right)$ and anxiety $\left(\mathrm{F}_{1,807}=27.56, \mathrm{p}<0.001\right)$. The interaction between the two knowledge variables was not significant for any of the outcomes.

To rule out the possibility that between-group differences might be attributable to demographic factors, we repeated the $2 \times 2$ analyses controlling for demographic differences between the groups. There were between-group differences in age $\left(\chi_{6}^{2}=13.23, \mathrm{p}=0.04\right)$, subject being studied $\left(\chi^{2}{ }_{6}=65.17\right.$, $\mathrm{p}<0.001)$ and previous awareness of $\operatorname{HPV}\left(\chi_{3}^{2}=94.77\right.$, $\mathrm{p}<0.001$ ), but not in marital status, ethnic group or practising of religion. When the three demographic factors were entered as covariates, the pattern of associations was unchanged.

\section{DISCUSSION}

This study was designed to test two hypotheses: (1) women who know that HPV is sexually transmitted will expect to experience higher levels of stigma, shame and anxiety if they test positive than women who are not aware of the mode of transmission; and (2) women who are aware of the high prevalence of HPV infection will expect to experience lower levels of stigma, shame and anxiety than women who underestimate the prevalence of infection. Participants were asked to think hypothetically about testing positive for HPV, and were given varying amounts of information about the virus to ensure that we could divide them according to their knowledge into four groups varying in both prevalence and mode of transmission.

In line with our first hypothesis, awareness that HPV is sexually transmitted was associated with significantly higher levels of stigma and shame, indicating that women respond to HPV in a way similar to other STIs. This is consistent with previous qualitative findings. ${ }^{8}$ However, knowledge of STI did not affect anxiety, and the pattern of results in fig 1 indicates that higher knowledge is associated with lower anxiety: women who were aware of both the prevalence and cause of HPV were the least anxious. Women receiving less information may have focused more on the link between HPV and cervical cancer, so their higher anxiety reflected concerns about cancer rather than HPV or sexual transmission.

We also found support for our second hypothesis; knowledge of prevalence had considerable associations with all three outcome measures, suggesting that the high prevalence of HPV is important information to convey to women undergoing HPV testing. The lower stigma and shame scores in the women who were aware of the high prevalence of HPV suggest that this information might have a "normalising" effect. The lower anxiety in this group is consistent with previous experimental work which has found that common illnesses are perceived as less serious. ${ }^{12}$

The retrospective tests showed important differences between the "STI only" group and the "STI and prevalence" 


\begin{tabular}{ll}
$\begin{array}{l}\text { Table } 2 \text { Demographic characteristics of the sample } \\
(\mathrm{n}=811)\end{array}$ & $\mathrm{n}(\%)$ \\
\hline & \\
\hline Age (years) & $251(30.9)$ \\
$18-20$ & $310(38.2)$ \\
$21-23$ & $250(30.9)$ \\
$24-30$ & \\
Marital status & $622(76.7)$ \\
Single & $185(22.8)$ \\
Married/cohabiting & $4(0.5)$ \\
Separated/divorced & \\
Ethnic group & $98(12.1)$ \\
Asian/Asian British & $18(2.2)$ \\
Black/black British & $39(4.8)$ \\
Mixed & $61(7.5)$ \\
Chinese & $384(47.3)$ \\
White British & $171(21.1)$ \\
White other & $19(2.3)$ \\
Other & $21(2.6)$ \\
Do not wish to answer & \\
Practising religion & $229(36.9)$ \\
No religion & $241(29.7)$ \\
Yes, practising & $259(31.9)$ \\
Stated religion but not practising & $12(1.5)$ \\
Missing* & \\
Subject being studied & $308(38.0)$ \\
Arts & $326(40.2)$ \\
Sciences (excluding medicine) & $177(21.8)$ \\
Medicine & \\
Previous awareness of HPV & $471(58.1)$ \\
Yes & $340(41.9)$ \\
No & \\
\hline & \\
\hline
\end{tabular}

*These participants stated a religion but answered "NA" to whether they were practising, making it impossible to code them in this variable.

group, with those in the second group having lower scores for shame and anxiety. Also important is the fact that among women who were aware that HPV is highly prevalent, also knowing it to be sexually transmitted was not associated with a significant increase in stigma or anxiety, although shame scores were higher in the group that knew that HPV is sexually transmitted. This supports the importance of ensuring that women are made aware of the high prevalence of HPV, given that they will likely be informed about its mode of transmission.

Provision of information in this study did not correspond precisely to knowledge because some women had prior awareness of HPV and were able to answer the knowledge questions correctly, without having been provided with the relevant information. Some women also answered the questions incorrectly, despite having been provided with the information (11\% of those given causal information and $13 \%$ of those given prevalence information). This shows that merely providing women with written information is not enough to ensure understanding (even in the short term), especially in an ethnically diverse group like our sample, ${ }^{\mathrm{ii}}$ and that further research is needed to find ways of communicating information about HPV effectively.

This study has several limitations. Participants had not actually taken part in HPV testing, so their responses to a positive result were hypothetical. Although this provides an indication of the association between knowledge of HPV and

ii $\chi 2$ tests confirmed that those answering the questions wrong despite having been provided with the relevant information were more likely to be from non-white ethnic groups.

\section{Box 2 Knowledge categorisation into four groups}

- Group 1 ( $n=138)$ : No knowledge of prevalence or sexual transmission (unaware of the prevalence or that human papilloma virus (HPV) is sexually transmitted).

- Group $2(n=245)$ : sexually transmitted infection (STI) only (aware that HPV is sexually transmitted but unaware of its high prevalence).

- Group $3(n=121)$ : prevalence only (aware of the high prevalence of HPV but unaware that it is sexually transmitted).

- Group 4 ( $n=307)$ : STI and prevalence (aware of both the high prevalence and the mode of transmission).

the effect of a test result, we cannot be certain that these results would generalise to a clinical setting. However, the results are consistent with previous qualitative research on women who had tested positive for HPV. ${ }^{8}$ The use of a student sample, and especially one made up largely of science and medical students, may limit the generalisability of the findings. Students are an important group to study, given the high prevalence of HPV infection in young women, ${ }^{1}$ but future research might target those from non-medical specialties, which would probably reduce the high awareness of HPV among participants. We may have preferentially recruited women who knew about HPV as the front page of the survey mentioned the virus and may have been disconcerting to those who had not heard of it, but we tried to minimise the effect this might have had by using actual knowledge of HPV to categorise participants for analysis, and by controlling for prior awareness in the analyses.

\section{Implications}

Our findings indicate that public health messages that raise women's awareness of the sexually transmitted nature of HPV may increase their feelings of stigma and shame if they test positive for the virus. But ensuring that women are aware that HPV is highly prevalent seems to reduce these negative feelings, and to reduce overall anxiety. If these findings can be replicated in women taking part in HPV testing, they point to the need for an emphasis on information about the high prevalence of HPV in public health messages and indicate that this information on prevalence could mitigate most of the negative psychosocial consequences of publicising the fact that HPV is sexually transmitted.

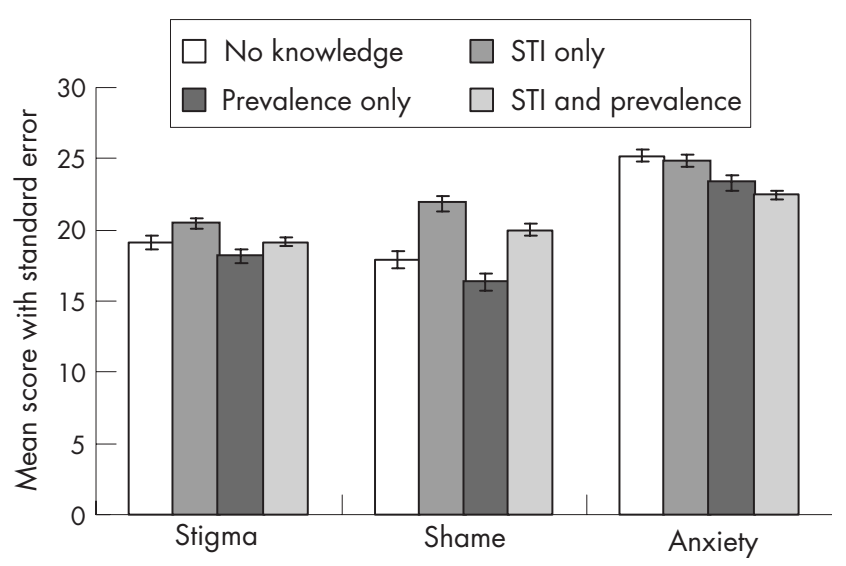

Figure 1 Mean scores for stigma, shame and anxiety for each group, with standard error bars. 


\section{ACKNOWLEDGEMENTS}

We thank Mark Livermore for the programming and all the women who took part in the survey.

\section{Authors' affiliations}

J Waller, L A V Marlow, J Wardle, University College London, London, UK Funding: This study was funded by Cancer Research UK. LM and JW are supported by Cancer Research UK. JOW is supported by a joint Economic and Social Research Council and Medical Research Council fellowship.

Competing interests: None declared.

\section{(6)}

\section{OPEN ACCESS}

Open Access This is an Open Access article distributed in accordance with the terms of the Creative Commons Attribution (CC BY 3.0) license, which permits others to distribute, remix, adapt and build upon this work, for commercial use, provided the original work is properly cited. See: http://creativecommons.org/licenses/by/3.0/

\section{REFERENCES}

1 Kitchener HC, Almonte M, Wheeler $\mathrm{P}$, et al. HPV testing in routine cervical screening: cross sectional data from the ARTISTIC trial. Br J Cancer 2006;95:56-61.

2 Bosch FX, Lorincz A, Munoz N, et al. The causal relation between human papillomavirus and cervical cancer. J Clin Pathol 2002;55:244-65.
3 Merck. European Commission approves Gardasi ${ }^{\circledR}$, Merck's cervical cancer vaccine 2006. http://www.merck.com/newsroom/press_releases/product/ 2006_0922a.html (accessed 24 Oct 2006).

$4 \mathrm{CDC}$. CDC's advisory committee recommends human papillomavirus vaccination. 2006. http://www.cdc.gov/od/oc/media/pressrel/r060629.htm (accessed 24 Oct 2006)

5 Waller J, McCaffery K, Forrest S, et al. Awareness of human papillomavirus among women attending a well woman clinic. Sex Transm Infect 2003;79:320-2.

6 Duncan B, Hart G, Scoular A, et al. Qualitative analysis of psychosocial impact of diagnosis of Chlamydia trachomatis: implications for screening. BMJ 2001;322:195-9

7 Fortenberry JD, McFarlane M, Bleakley A, et al. Relationships of stigma and shame to gonorrhea and HIV screening. Am J Public Health 2002;92:378-81.

8 McCaffery K, Waller J, Nazroo J, et al. Social and psychological impact of HPV testing in cervical screening: a qualitative study. Sex Transm Infect 2006;82:169-74.

9 McCaffery K, Waller J, Forrest S, et al. Testing positive for human papillomavirus in routine cervical screening: examination of psychosocial impact. BJOG 2004;111:1437-43.

10 Maissi E, Marteau TM, Hankins M, et al. The psychological impact of human papillomavirus testing in women with borderline or mildly dyskaryotic cervical smear test results: 6-month follow-up. Br J Cancer 2005;92:990-4.

11 Jones EE, Farina A, Hastorf AH, et al. Social stigma: the psychology of marked relationships. New York: WH Freeman and Company, 1984.

12 Ditto PH, Jemmott JB III. From rarity to evaluative extremity: effects of prevalence information on evaluations of positive and negative characteristics. J Perspect Soc Psychol 1989:57:16-26.

13 Cunningham SD, Tschann J, Gurvey JE, et al. Attitudes about sexual disclosure and perceptions of stigma and shame. Sex Transm Infect 2002;78:334-8.

14 Cunningham SD, Kerrigan D, Pillay KB, et al. Understanding the role of perceived severity in STD-related care-seeking delays. J Adolesc Health 2005;37:69-74. 